\title{
Assessment of Self-medication Practices in Urban and Rural areas of Kalaburagi, Karnataka
}

\author{
SS Biradar, Sushruta Marla*, Chaitanya K, Himaja S, Chandini M \\ HKES Matoshree Taradevi Rampure Institute of Pharmaceutical Sciences, Gulbarga, Karnataka, INDIA.
}

Received: 23 March 2018;
Accepted: 27 May 2018
*Correspondence to:
Ms. Sushruta Marla, Department of Pharmacy Practice, HKES Matoshree Taradevi Rampure Institute of Pharmaceutical Sciences, Gulbarga, Karnataka, INDIA. Email:sushruta17@gmail.com

Copyright: (c) the author(s),publisher and licensee Indian Academy of Pharmacists. This is an open-access article distributed under the terms of the Creative Commons Attribution Non-Commercial License, which permits unrestricted non-commercial use, distribution, and reproduction in any medium, provided the original work is properly cited.

\begin{abstract}
Background: Self-medication can be defined as the use of drugs to treat self-diagnosed disorders or symptoms. In India, the rate of self-medication practices is rising exponentially as it is the cheapest way of treatment. But improper self-diagnosis and improper use of drugs is major part of concern these days. The wrong usage of medications is creating medication hazards, drug toxicities, drug interactions drug-food interactions etc. Methodology and Results: The present study enrolled total of 500 people (250 urban and 250 rural), of which, the age group of 36-45 consumed more self- medication both in urban (29.5\%) and rural $(24.40 \%)$ population. The illiterate $(64.56 \%)$ people practiced more self- medication in rural areas where as in urban graduates $(33.87 \%)$ practiced more self-medications. lower middle class $(49.60 \%)$ people practiced higher self-medication in rural and upper class $(67.21 \%)$ people practiced higher self-medication in urban. Analgesics and antipyretics drugs were most frequently used drugs in both urban and rural areas. Thereafter the self - medication population was divided into test and control group. The test group was given both pills and counselling whereas control group was given only pills, both groups were compared. After intervention, it was found that $30.50 \%$ self-medication dropped in urban test group, and $10.00 \%$ in the urban control group. In rural test group $36.00 \%$ of drop was observed in self-medication practices whereas in rural control group it was only $9.60 \%$. Conclusion: Counselling played important role in reduction of self-medication practices in both urban and rural areas.
\end{abstract}

Key words: Self-medication, Urban population, Rural Population, Medication hazards, India.

\section{INTRODUCTION}

Self-medication is determined as "utilization of pharmaceutical or medicinal products by the consumer to handle self-recognized disorders or symptoms. Recurrent use of previously prescribed medication without doctor's advice, or the purpose of medication recommended by lay sources or health workers not entitled to prescribe medicine". ${ }^{[1]}$

Self-medication is very common and a number of reasons could be enumerated for it. Such as urge of self-care, feeling of sympathy towards family members in sickness, lack of health services, poverty, ignorance, missbelief, extensive advertisement and availability of drugs in other than drug shops are responsible for the growing trend of self-medication. ${ }^{[2]}$

Prevalence of self-medication in developing countries was found to be $12.7 \%$ to $95 \% \cdot{ }^{[3-4]}$ In India it was found to be $31 \% \cdot{ }^{[5]}$ Another article revealed that in India, the reason for self-medication in $35.48 \%$ of male \& $15.56 \%$ of female was lack of time, $32.26 \%$ of male $\& 26.67 \%$ of female used self-medication due to high consultant fee of physician, $29.03 \%$ of male \& $11.11 \%$ of female wants quick relief. ${ }^{1}$ The prevalence of self-medication in Karnataka region was found to be $88.6 \%$ of them results show $47.06 \%$ due to knowledge about illness \& its treatment, $44.12 \%$ as a time saving factor, $8.82 \%$ due to prescriber's ineffective medications. ${ }^{[6]}$

Modern medicine has become absorbed rapidly into the local custom throughout the world and misused for a wide range of applications. Here misuse is defined as using an OTC product for a legitimate medical reason, but in higher doses or for a longer period than recommended ex: taking more of a painkiller than recommended to treat a head ache. ${ }^{[2]}$

1. Incorrect self-diagnosis. Failure to recognize or self-diagnosis contraindications, interactions, warnings \& precautions.

2. Failure to recognize that the same active substance is already being taken under a different name.

3. Food and drug interaction.

4. At community level, improper self-medication could result in an increase in drug induced disease and in wasteful public expenditure. ${ }^{[7]}$

\section{Role of Pharmacists}

A pharmacist can play a key role in giving advice to consumers on the proper and safe use of medicinal products intended for self-medication. In other words pharmacist play a valuable role in identifying, solving \& preventing drug related problems (DRPs) for the purpose of achieving optimal patient outcomes and quality of life. ${ }^{[8]}$ A pharmacist could play role of a communicator, quality drug supplier, trainer, supervisor, collaborator and health promoter. ${ }^{[9]}$

Rate of self-medication practices rising exponentially as it is cheap way of treatment. But improper self-diagnosis and improper use of drugs like dosage interval, dosage form, use of antibiotics, route of administration etc., are major part of concern these days. The wrong usage of medications 
creates medication hazards, drug toxicities, drug-drug interactions drug-food interactions etc. Hence there is an urgency to study the prevalence of selfmedications, educate people and create awareness regarding proper usage of OTC medications in Kalaburagi and Hebbal, it is also necessary to avoid medication hazards.

The objective of study was to assess self-medication practices in urban and rural areas of Gulbarga. Commonly used drugs and demographic details of self-medicating population were assessed. Counselling on self-medication was done and effect of counselling was studied.

\section{METHODOLOGY}

A prospective observational study was carried out on 500 people (250 urban and 250 rural) for a period of six months, at the Kalaburagi and Hebbal, (a rural area in Kalaburagi district), Karnataka. People of either sex, age $>18$. willing to participate, were included in study. Doctors, Pharmacists and Medical students were excluded from study. 250 subjects from urban and 250 subjects from rural areas of kalaburgi were randomly selected. The study was initiated after obtaining clearance from Ethical Committee (2016). The population enrolled in the study by considering the study criteria after taking their written consent to participate in the study. Demographic details were collected in a specially designed data collection form. The population of both urban and rural areas were divided individually into two groups a test group and control group. The test group received counselling and pills, whereas, control group received only pills. After creating a baseline, counselling along with the pills was given to test groups, whereas, a control group was provided with only pills. Thereafter follow up was done to know the effectiveness of

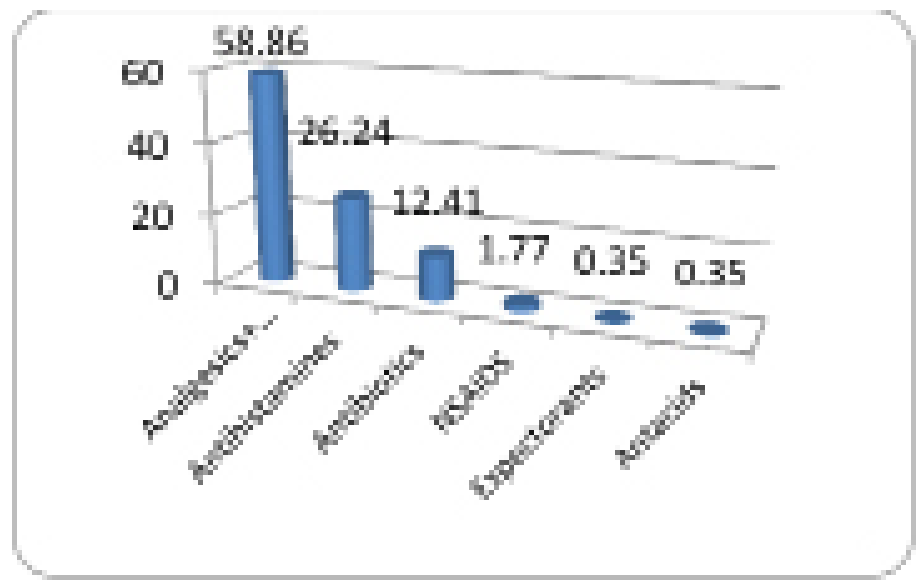

Figure 1:Frequencies of drug classes commonly used for selfmedication.

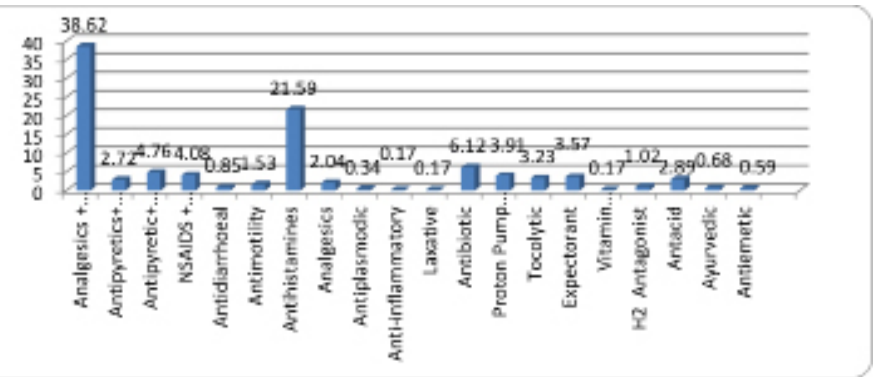

Figure 2: Frequencies of drug classes commonly used for selfmedication.

\begin{tabular}{|c|c|c|c|c|}
\hline Character & & Rural \% & Urban \% & $\begin{array}{l}\text { Test of } \\
\text { significance }\end{array}$ \\
\hline \multirow[t]{2}{*}{ Self- medication } & Self- medication & 50.8 & 73.2 & \multirow{2}{*}{$\begin{array}{l}\mathrm{X}^{2}=26.6 \\
\mathrm{P}<0.001 \\
\text { Highly } \\
\text { Significant }\end{array}$} \\
\hline & Non Self- medication & 49.2 & 26.8 & \\
\hline \multirow[t]{2}{*}{ Gender } & Male & $77.6 \%$ & $66.4 \%$ & \\
\hline & Female & $22.4 \%$ & $33.6 \%$ & \\
\hline \multirow[t]{8}{*}{ Age } & $16-25$ & 3.14 & 9.28 & \\
\hline & $26-35$ & 22.04 & 18.57 & \\
\hline & $36-45$ & 24.40 & 29.5 & \\
\hline & $46-55$ & 20.47 & 20.2 & \\
\hline & $56-65$ & 19.68 & 15.3 & \\
\hline & $66-75$ & 6.29 & 6.04 & \\
\hline & $76-85$ & 0.78 & 1.09 & \\
\hline & $86-95$ & 3.15 & 00 & \\
\hline \multirow{6}{*}{$\begin{array}{l}\text { Educational } \\
\text { status }\end{array}$} & Illiterate & 64.56 & 8.74 & \multirow{6}{*}{$\begin{array}{l}X^{2}=149 \\
P<0.001 \\
\text { Highly } \\
\text { significant }\end{array}$} \\
\hline & Primary & 12.59 & 4.91 & \\
\hline & High School & 12.59 & 12.02 & \\
\hline & Intermediate & 8.66 & 21.31 & \\
\hline & Graduate & 1.57 & 33.87 & \\
\hline & Postgraduate & 0 & 19.12 & \\
\hline \multirow[t]{5}{*}{$\begin{array}{l}\text { Socioeconomic } \\
\text { status }\end{array}$} & Class I & 0 & 67.21 & \multirow{5}{*}{$\begin{array}{l}X^{2}=209 \\
P<0.001 \\
\text { Highly } \\
\text { significant }\end{array}$} \\
\hline & Class II & 8.66 & 22.40 & \\
\hline & Class III & 23.62 & $4.91 \%$ & \\
\hline & Class IV & 49.60 & $4.37 \%$ & \\
\hline & Class V & 18.11 & $1.09 \%$ & \\
\hline \multirow[t]{2}{*}{ Language } & Hindi & 7.81 & $16.30 \%$ & \\
\hline & Kannada & 92.18 & 83.69 & \\
\hline \multirow[t]{8}{*}{ Habits } & No Habits & $54.8 \%$ & 68 & \\
\hline & Alcohol & $16 \%$ & 4 & \\
\hline & Smoking & $2.4 \%$ & 11.2 & \\
\hline & Tobacco & $22.4 \%$ & 0.8 & \\
\hline & Alcohol+ Smoking & $0.4 \%$ & 12.4 & \\
\hline & Alcohol+ Tobacco & $0.8 \%$ & 1.6 & \\
\hline & Smoking+ Tobacco & $6.24 \%$ & 1.2 & \\
\hline & $\begin{array}{l}\text { Alcohol+ Smoking+ } \\
\text { Tobacco }\end{array}$ & $0.8 \%$ & 0.8 & \\
\hline
\end{tabular}

counselling on both test groups in comparison to control groups of urban and rural areas. The data were analysed by using Proportions and Chi-Square test. The per capita monthly income of the family has been calculated using Modified B. G. Prasad's Criteria 2016 for Classification of Socioeconomic Status (latest version 2016).

\section{RESULTS}

The kalaburgi(urban) and hebbal (rural) population was enrolled in study. 250 subjects from each urban and rural were interviewed using pretested questionnaire, results are as follows.

In rural areas, out of 250 participants 127 (50.8\%) people were taking self-medications, among which median age group was 36-45. Major selfmedicating population was illiterate i.e., $64.56 \%$. Most of the population 
Table 2: Comparing use of self- medication before and after intervention ( 250 urban and 250 rural population was considered).

\begin{tabular}{|l|l|l|l|l|} 
& $\begin{array}{l}\text { Before intervention } \\
\text { Rural }\end{array}$ & $\begin{array}{l}\text { After intervention } \\
\text { Rural }\end{array}$ & $\begin{array}{l}\text { Before intervention } \\
\text { Urban }\end{array}$ & $\begin{array}{l}\text { After intervention } \\
\text { Urban }\end{array}$ \\
\hline $\begin{array}{l}\text { No. Of people taking self- } \\
\text { medication }\end{array}$ & $50.8 \%$ & $39.2 \%$ & $73.2 \%$ & $58.4 \%$ \\
\hline
\end{tabular}

There was decrease in the practice of self- medication both in urban and rural population after counselling. It was decreased from $50.8 \%$ to $39.2 \%$ in rural areas and in urban areas decrease was from $73.2 \%$ to $58.4 \%$.

Table 3: Comparative decrease in self-medication in test and control groups after intervention

\begin{tabular}{|l|l|l|l|l|l|}
\hline & Group & Urban population & Urban population (\%) & Rural population & Rural population (\%) \\
\hline \multirow{2}{*}{$\begin{array}{l}\text { Self-medication after } \\
\text { intervention }\end{array}$} & Test & 64 & $69.5 \%$ & 41 & $64 \%$ \\
\cline { 2 - 6 } & Control & 82 & $90 \%$ & 57 & $90.4 \%$ \\
\hline
\end{tabular}

belonging to class 4 social economic status, and in urban area out of 250 participant's $183(73.2 \%)$ people are taking self-medication, among which median age group was 36-45. Major self-medicating population was graduates i.e., $33.87 \%$ and most of them belongs to class 1 social economic status.

Urban population $(\mathbf{7 3 . 2} \%$ ) practiced more self-medication compared to rural population $(\mathbf{5 0 . 8 \%})$. In our study the most commonly used drugs were antipyretics and analgesics i.e., in rural 166 (58.85\%) antipyretics and analgesics and in urban 233 (38.62) antipyretics and analgesics.

We divided entire self-medicating population into test and control group in urban ( 92 people in the test group and 91 people in control group) and rural areas (64 people in the test group and 63 people in control group). Only pills were provided to control group whereas, test group aided with pills along with counselling. The decrease in self-medication practices in test group was more compared to control group in urban and rural areas. In rural population $9.6 \%$ of decrease in self-medication practices was observed in control group, $36 \%$ in test groups. In urban population $10 \%$ decrease was seen in control group and $30.5 \%$ in test group.

\section{DISCUSSION}

The present study was carried out in Kalaburgi (urban) and Hebbal (rural) areas to assess the self-medication practices. We enrolled 500 subjects randomly, i.e., 250 from urban and 250 from rural. In urban area $166(66.4 \%)$ were male and $84(33.60 \%)$ were female, in rural areas males were $194(77.6 \%)$ and females were 56 (22.4\%). Males were the major responders in our study. We enrolled people above age group of 18 as per study criteria and widely distributed up to age 100 . More number of participants was aged in between 36 to 45 in both urban and rural areas, irrespective of their gender. As age and gender distribution was uneven, there was no significance.

In urban area out of 250 people, $183(73.2 \%)$ were practicing selfmedication and in rural out of 250 people, $127(50.80 \%)$ were practicing self-medication. Self-medications in urban areas was higher than in rural. The association between self-medicating and non-self-medicating population was found to be highly significant $(\mathrm{P}<0.001)$. In urban area literacy has shown a significant role on self-medication practices, as graduates $(33.87 \%)$ and intermediates $(21.31 \%)$ were practicing high self-medication. In rural area literacy had no influence as illiterates $(64.56 \%)$ were majorly practicing self-medication. The association between self-medication practices and literacy rate of population was found to be highly significant $(\mathrm{P}<0.001)$. Majority of participants in urban areas belonged to upper class i.e., class-I (67.21\%) whereas in rural areas majority of participants belonged to lower middle class i.e., class-IV (49.60). The association between self-medication practices and socio-economic status of population was found to be highly significant $(\mathrm{P}<0.001)$. In both urban and rural areas the majority of drugs consumed belonged to class analgesic and antipyretics $38.62 \%$ in urban and $58.86 \%$ in rural).

According to study by Varun $\mathrm{k}$ et al..$^{[1]}$ in urban areas of Delhi 236 participants were enrolled, out of which 219(92.8\%) took selfmedication. Kuppuswamy's socio-economic classification (2012) revealed $61.00 \%$ of self-medicating population belongs to upper middle class. Self-medication was found to be practiced more among youngsters than the older age group persons. Graduates and postgraduates practiced self-medication more than others. Common cold and fever were the most common ailments for which self-medication were practiced. Paracetamol and cough syrups were the most commonly used class of drugs.

According to another survey by Neha L et al. ${ }^{[10]}$ in urban population of pune, they enrolled 300 people under study out of which 258 (86\%) were practicing self-medication. Out of which males were $51.55 \%$ and females were $48.45 \%$. The study revealed that the drugs that are commonly self-medicated were: analgesics (28.68\%), antibiotics (13.18\%), vitamins $(10.85 \%)$ and GIT ailment drugs (14.34).

A study was conducted in rural areas of Medak district by Santosh K and Kavita D. ${ }^{[11]}$ They involved 1800 subjects, in which $1200(80 \%)$ practicing self-medication. In which males were $66 \%$ and females were $34 \%$. Most of the patients were seeking self-medication for headache and other pain (23.3\%), fever (14.5\%), urinary tract infections $(9.7 \%)$ and respiratory tract infections $(11.7 \%)$. The drugs most commonly used are NSAIDs (25.3\%) and antibiotics (16.7\%). Prevalence of selfmedication was high primarily among illiterate males.

A cross sectional study was conducted by Hasan Najmul and Barar Kiran $\mathrm{V}^{[12]}$ in urban areas of Bikaner involving 365 participants. Self-medication prevalence was found to $82.1 \%$. Antipyretics and analgesics were commonly consumed medications for fever, cough, cold and headache. Antispasmodic, anti-allergic and antacids were other commonly consumed groups. People self-medicated for minor illness from medical shops. 
There after we divided our self- medication practicing population in to test and control group i.e., in urban population 92 into test and 91 into control where as in rural population 64 into test and 63 into control. Then test groups are aided with pills and counselling and control group aided with only pills. After intervention we found decrease in self-medication practices in test group more compared to control group in both urban and rural areas i.e., in rural population $9.6 \%$ in control group and $36 \%$ in test group and in urban population $10 \%$ in control group and $30.5 \%$ in test group. Intervention was more effective in rural area compared to urban area.

\section{CONCLUSION}

Present study shows, pharmacist intervention and patient counselling shows improvement in attitude of people regarding self-medication practices. It is highly vital to set up more strategies which may bring complete awareness and high impact on behaviour of population towards self-medication for better outcomes thereby improving the quality of life.

\section{ACKNOWLEDGEMENT}

None.

\section{ABBREVIATION}

None.

\section{CONFLICT OF INTEREST}

None.

\section{REFERENCES}

1. Varun K, Abha M, Geeta Y, Deepak R, Sudan S. Prevalence and pattern of self- Medication practices in an urban area of Delhi, India. Med J DY Patil Univ 2015;8(1):16-20.

2. Sonam J, Reetesh M, Jeetendra K. Concept of Self Medication: A Review. Int J Pharm Biol Archives. 2011;2(3):831-6.

3. Kasilo OJ, Nhachi CF, Mutangadura EF. Epidemiology of household medications in urban Gweru and Harare. Cent Afr J Med. 1991;37(6):167-71.

4. Figueiras A, Caamano F, Gestal OJ. Socio-demographic factors related to selfmedication in Spain. Eur J Epidemiol. 2000;16(1):19-26.

5. Deshpande SG, Tiwari R. Self-medication-a growing concern. Indian J Med Sci. 1997;51(3):93-6.

6. Pushpa R, Ravindra L, Rohini D. Prevalence and predictors of self-medication in a selected urban and rural district of Sri Lanka. WHO South-East Asia J Public Healt 2012;1(1):28-41.

7. Darshana B, Self-medication: A current challenge. J of Basic and Clin pharm 2014;5(1):19-23.

8. Wilbur K, Salam SE, Mohammadi E. Patient perceptions of pharmacist roles in guiding self-medication of over-the-counter therapy in Qatar. Patient Prefer Adherence. 2010;4(1):87-93

9. Hernandez-Juyol M, Job-Quesada JR. Dentistry and self-medication: A current challenge. Med Oral. 2002;7(1):344-7.

10. Neha L, Yogendra K, Radha Y, Mukesh D, Avanti B, Apoorva M. Selfmedicationin urban population of Pune, Maharashtra, India. Sch J App Med Sci. 2013;1(6):732-8

11. Kumar S, Kavitha B, Bhukya D. To estimate the prevalence of self-medication in rural areas of Medak District of Telangana. Indian J Appl Res. 2014;6(3):19-23.

12. Najmul $\mathrm{H}$, Kiran BV. Determinants of self-medication practice in the communities of urban areas of Bikaner, Rajasthan. J Pharm Res. 2014;13(2):45-9.

Cite this article as: Biradar SS, Marla S, Chaitanya K, Himaja S, Chandini M. Assessment of Self-medication Practices in Urban and Rural areas of Kalaburagi, Karnataka. J Pharm Pract Community Med. 2018;4(2):117-20. 